УДК 663.251

DOI 10.30679/2219-5335-2020-2-62-113-121

ОЦЕНКА ЦВЕТА

РОЗОВЫХ ВИН

С ПОМОЩЬЮ СИСТЕМЫ СIЕLАВ

\author{
Червяк София Николаевна \\ канд. техн. наук \\ научный сотрудник \\ лаборатории химии \\ и биохимии вина \\ e-mail: Sofi4@list.ru
}

Федеральное государственное

бюджетное учреждение науки

«Всероссийский начиональный

научно-исследовательский институт

виноградарства и виноделия «Магарач» $Р A Н »$, Ялта, Республика Крым, Россия

Широкий сортимент винограда, используемый для производства розовых вин, а также технологические особенности его переработки приводят к получению готовой продукции с цветовыми характеристиками от бледно-розовой до клубничной. Изменчивость цвета розовых вин в пределах одного наименования продукции разных партий может вызывать сомнение потребителя относительно происхождения и качества напитка. Перспективным способом придания количественного выражения цвету вина в целях дальнейшего его воспроизведения является использование системы CIELab. В работе приведены результаты экспериментального сопоставления органолептических и инструментальных методов оценки цвета вин. Исследования проводили на образцах розовых столовых сухих вин из винограда сортов КабернеСовиньон, Саперави, Бастардо магарачский, Санджовезе. Воспроизведение трихроматических координат $\mathrm{L}^{*}, \mathrm{a}^{*}, \mathrm{~b}^{*}$ осуществляли с помощью конвертера цвета. Показано, для образцов вин из винограда сортов Каберне-Совиньон, Бастардо магарачский и Санджовезе характерна пастельная гамма, а в винах из Саперави
UDC 663.251

DOI 10.30679/2219-5335-2020-2-62-113-121

\section{ASSESSING THE COLOR OF ROSÉ WINES WITH THE CIELAB SYSTEM}

\author{
Cherviak Sofia Nikolaevna \\ Cand. Techn. Sci. \\ Research Associate \\ of Wine Chemistry and Biochemistry \\ Laboratory \\ e-mail: Sofi4@list.ru \\ Federal State Budget \\ Scientific Institute \\ "All-Russian National \\ Research Institute of Viniculture \\ and Winemaking «Magarach» of RAS», \\ Yalta, Republic of Crimea, Russia
}

A large assortment of grapes used for the production of rosé wines, along with technological processing peculiarities result in the final product with colour characteristics ranging from pale pink to dark crimson. Colour variability of rosé wines within the same product name of different batches may raise consumer's doubts as to the origin and quality of a beverage. CIELab system is a promising way to wine colour quantitative expression with a view to its reproduction. The paper presents data on experimental comparison of organoleptic and instrumental methods for wine colour assessment. The study was conducted on samples of rosé table dry wines from 'Cabernet Sauvignon', 'Saperavi', 'Bastardo Magarachsky' and 'Sangiovese' grapes. Colour converter was used for reproduction of $\mathrm{L}^{*}, \mathrm{a} *, \mathrm{~b} *$ trichromatic coordinates. It was shown that wine samples from 'Cabernet Sauvignon', 'Bastardo Magarachsky' and 'Sangiovese' grapes were characterized by pastel colours, while Saperavi wines demonstrated 
Плодоводство и виноградарство Юга России № 62(2), 2020 г.

отмечается наличие розовых и клубничных оттенков, что обусловлено как сортовыми особенностями винограда, так и физикохимическим составом вин. Общее содержание фенольных веществ в образцах розовых вин может различаться в $1,5-3$ раза и составлять от 350 до $912 \mathrm{мг} /$ дм³ $^{3}$.

Сопоставление визуальных и инструментальных методов оценки цвета вин показало большое сходство описательного и цветового выражения цвета исследуемых образцов. Система CIELab может использоваться для математического выражения цвета вина, репродуцирования изображения

и воспроизведения цвета, что в дальнейшем может использоваться для регулирования и управления качества розовых вин.

Ключевые слова: ВИНО, ОПТИЧЕСКИЕ ПОКАЗАТЕЛИ, ЦВЕТОВОЕ ВЫРАЖЕНИЕ, МОНОМЕРНЫЕ АНТОЦИАНЫ pink and raspberry shades due to both the varietal characteristics of the grapes and the physical-chemical composition of the wines. The total content of phenolic substances in the samples of rosé wines can vary by 1.5-3 times, and range from 350 to $912 \mathrm{mg} / \mathrm{dm}^{3}$. Comparison of the visual and instrumental colour assessment methods demonstrated strong similarities between descriptive and colour expression of the studied samples color. The CIELab system can be used to mathematically express the colour of a wine, reproduce an image and colour, which can be used to regulate and manage the control of rosé wines.

Key words: WINE, CHROMATIC PROPERTIES, COLOR EXPRESSION, MONOMERIC ANTHOCYANINS

Введение. Одним из путей повышения имиджа предприятия является выпуск продукции стабильного качества. Эффективным способом реализации заявленных особенностей и свойств продукции может служить стандартизация потребительских характеристик вина. На сегодняшний день одним из приоритетных направлений винодельческой отрасли в Европе и мире является увеличение ассортимента и объема розовых столовых и игристых вин ввиду возрастания спроса на данный вид продукции [1-4]. В то же время цвет розовых вин может варьировать в широком диапазоне спектра и, согласно ГОСТ 32051, характеризуется как бледно-розовый, розовый, темно-розовый, цвет молодой лососины и др. [5]. Согласно другим источникам окраска данного типа вина также описывается как пурпурнорозовая, розовая, лососевая, оранжевая и цвета луковой шелухи [6-9].

Однако органолептическая оценка цветовых характеристик является достаточно субъективной процедурой, так как зависит от многих факторов: освещения и восприятия человека, его физического и психологического состояния $[10,11]$. Кроме того, для описания цвета вин существует достаточно много синонимичных понятий и терминов, в связи с чем интерпре- 
Плодоводство и виноградарство Юга России № 62(2), 2020 г.

тация данных, полученных путем визуальной оценки, является весьма затруднительной, а воспроизведение - невозможным [11, 12].

Перспективным способом решения проблемы воспроизведения окраски вин является придание количественного выражения цвету с помощью цветового пространства CIELab [10, 13-15].

Объекты и методы исследований. Объектами исследований являлись образцы розовых столовых сухих вин урожая 2018 года из винограда сортов Каберне-Совиньон, Саперави, Санджовезе, Бастардо магарачский. Вина были приготовлены в условиях микровиноделия по следующей технологической схеме: дробление винограда с гребнеотделением $\rightarrow$ прессование мезги и отделение сусла-самотека и первой прессовой фракции в ко-

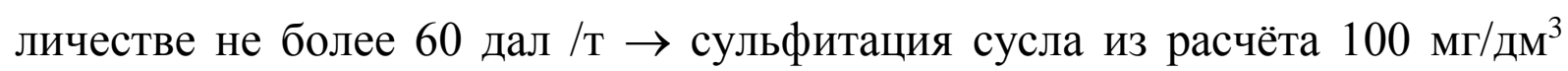
общего диоксида серы $\rightarrow$ брожение при температуре $18-22{ }^{\circ} \mathrm{C}$ на расе дрожжей 47-К из коллекции микроорганизмов виноделия «Магарач» (КМВ «Магарач») до остаточных сахаров 30-50 г/дм³ $\rightarrow$ снятие с дрожжевого осадка $\rightarrow$ дображивание $\rightarrow$ сульфитация из расчёта 150 мг/дм³ общего диоксида серы. В приготовленных винах определяли объемную долю этилового спирта, массовые концентрации суммы фенольных веществ, мономерных антоцианов, титруемых кислот, $\mathrm{pH}[16,17]$.

Визуальное определение цветовых характеристик вин осуществляли методом органолептического анализа [5]. Для инструментальной оценки цвета вин применяли цветовое пространство CIELab $[8,18]$. Определение координат X, Y, Z осуществляли с помощью модифицированного метода Pérez-Caballero V. et al. c учетом оптической плотности образцов при длинах волн 450, 520, 570 и 630 нм [19]. Определение соответствующих цветовых выражений вин на основе трихроматических координат $\mathrm{L}^{*}$, $\mathrm{a}^{*}$, b* осуществляли с помощью конвертера цвета [20]. Обработку полученных экспериментальных данных проводили с использованием программы SPSS Statistica 17.0. 
Плодоводство и виноградарство Юга России № 62(2), 2020 г.

Обсуждение результатов. Анализ физико-химических показателей вин показал (табл. 1), что все исследуемые образцы отвечали требованиям ГОСТ [21]. Объемная доля этилового спирта в винах варьировала от 11,3 до 13,1 \% об. при массовой концентрации титруемых кислот от 4,3 до 7,4 г/дм³ . Исследование фенольного комплекса вин показало, что общее содержание фенольных веществ в образцах розовых вин может различаться в 1,5-3 раза и составлять от 350 до 912 мг/дм³. В то же время необходимо отметить, что при одинаковом содержании фенольных веществ в образцах № 4 и № 5 доля мономерных антоцианов в них, отвечающих за окраску напитка, отличается в 1,5 раза.

Таблица 1 - Физико-химические показатели розовых вин

\begin{tabular}{|c|l|c|c|c|c|c|}
\hline \multirow{2}{*}{$\begin{array}{c}\text { № } \\
\text { образца }\end{array}$} & \multirow{2}{*}{$\begin{array}{c}\text { Сорт } \\
\text { винограда }\end{array}$} & $\begin{array}{c}\text { Объемная } \\
\text { доля } \\
\text { этилового } \\
\text { спирта, } \%\end{array}$ & $\begin{array}{c}\text { суммы } \\
\text { фенольных } \\
\text { веществ, } \\
\text { мг/дм }\end{array}$ & $\begin{array}{c}\text { мономерных } \\
\text { антоцианов, } \\
\text { мг/дм }\end{array}$ & $\begin{array}{c}\text { Массовая концентрация } \\
\text { кислот, } \\
\text { г/дм }^{3}\end{array}$ & $\mathrm{pH}$ \\
\hline 1 & Саперави & 11,3 & 655 & 145 & 6,1 & 3,6 \\
\hline 2 & $\begin{array}{l}\text { Каберне- } \\
\text { Совиньон }\end{array}$ & 12,4 & 704 & 489 & 7,4 & 3,1 \\
\hline 3 & Саперави & 11,6 & 912 & 466 & 6,6 & 3,4 \\
\hline 4 & Санджовезе & 13,1 & 346 & 120 & 4,3 & 3,5 \\
\hline 5 & $\begin{array}{l}\text { Каберне- } \\
\text { Совиньон }\end{array}$ & 12,7 & 353 & 189 & 5,6 & 3,5 \\
\hline 6 & $\begin{array}{l}\text { Бастардо } \\
\text { магарачский }\end{array}$ & 12,9 & 544 & 173 & 5,9 & 3,4 \\
\hline
\end{tabular}

Анализ колориметрических показателей розовых вин показал, что величина оптической плотности при длине волны 420 нм для всех образцов превышает аналогичные значения для $D_{520}$, что свидетельствует о преобладании желтых пигментов в цвете над красными (табл. 2). В процентном выражении значение $D_{520}$ составляет $45-72 \%$ от всей хроматической структуры вина. Доля синих пигментов в образцах № 1-4 варьирует незначительно: от 10 до 12 \%. Варианты опыта № 5 и № 6 характеризуются более низким содержанием свободных антоцианинов в хинонной форме или 
Плодоводство и виноградарство Юга России № 62(2), 2020 г.

комплекса танинов и антоцианов, что отражается на показателе $D_{620}$, доля которого составляет 5 и 7 \% соответственно [7].

Таблица 2 - Оптические показатели и визуальная характеристика вин

\begin{tabular}{|c|c|c|c|l|}
\hline \multirow{2}{*}{$\begin{array}{c}\text { № } \\
\text { образца }\end{array}$} & \multicolumn{3}{|c|}{ Оптическая плотность } & \multicolumn{1}{|}{$\begin{array}{c}\text { Визуальная характеристика } \\
\text { цвета }\end{array}$} \\
\cline { 2 - 4 } & $\mathrm{D}_{420}$ & $\mathrm{D}_{520}$ & $\mathrm{D}_{620}$ & \\
\hline 1 & 0,051 & 0,044 & 0,012 & Розово-персиковый \\
\hline 2 & 0,190 & 0,100 & 0,04 & Персиково-розовый \\
\hline 3 & 0,228 & 0,230 & 0,049 & Клубничный \\
\hline 4 & 0,010 & 0,007 & 0,002 & Персиковый \\
\hline 5 & 0,219 & 0,114 & 0,017 & $\begin{array}{l}\text { Кремовый с легким } \\
\text { розовым оттенком }\end{array}$ \\
\hline 6 & 0,109 & 0,031 & 0,011 & Кремовый с желтым оттенком \\
\hline
\end{tabular}

Результаты визуальной оценки розовых столовых вин наглядно демонстрируют разнообразие их цвета в зависимости от сорта винограда: от кремового с различными оттенками до клубничного. В образцах вин из винограда сортов Каберне-Совиньон, Бастардо магарачский и Санджовезе превалирует пастельная гамма с преобладанием персиковых и желтых оттенков. В то же время в винах из Саперави отмечается наличие розовых и клубничных оттенков, что легко объяснить особенностями сорта винограда и характерной окрашенной мякотью ягоды, что даже в условиях щадящего прессования мезги обеспечивает переход красящих компонентов в сусло. Полученные данные свидетельствуют о том, что путем регулирования сортового сортимента можно варьировать цветовые характеристики розовых вин.

Инструментальную оценку цвета вин осуществляли с помощью трехмерной системы координат CIELab, позволяющей репродуцировать изображения и воспроизводить одни и те же цвета независимо от особенностей устройства или аппаратных средств (монитора, принтера или компьютера).

Анализ данных показал, что значение светлоты L* в исследуемых образцах варьирует от 75,5 до 99,2 (табл. 3). Хроматическая координата а* в большинстве образцах не превышает 5, что свидетельствует о незначи- 
тельной доле красных пигментов. Значение показателя образца № 3 составляет 23,5 , что в визуальном описании подтверждается более интенсивным клубничным цветом по сравнению с другими вариантами. Величина хроматической координаты $\mathrm{b}^{*}$ для всех вин составляет более 0 и свидетельствует о превалировании в винах жёлтых тонов над синими.

Таблица 3 - Трихроматические характеристики вин

\begin{tabular}{|c|c|c|c|c|c|c|c|}
\hline $\begin{array}{c}\text { № } \\
\text { образца }\end{array}$ & $\mathrm{X}$ & $\mathrm{Y}$ & $\mathrm{Z}$ & $\mathrm{L}^{*}$ & $\mathrm{a}^{*}$ & $\mathrm{~b}^{*}$ & Цветовое выражение \\
\hline 1 & 84,33 & 86,26 & 88,81 & 94,42 & 4,86 & 2,65 & \\
\hline 2 & 60,26 & 62,00 & 49,12 & 82,92 & 3,52 & 16,44 & \\
\hline 3 & 55,40 & 49,10 & 40,41 & 75,51 & 23,53 & 13,39 & \\
\hline 4 & 93,31 & 97,89 & 103,52 & 99,18 & 0,86 & 1,01 & \\
\hline 5 & 68,18 & 67,37 & 49,74 & 85,69 & 9,6 & 20,59 & \\
\hline 6 & 83,37 & 88,39 & 76,55 & 95,32 & $-0,84$ & 13,27 & \\
\hline
\end{tabular}

Сравнительная оценка визуальных и инструментальных методов оценки цвета вин показала большое сходство описательного и цветового выражения цвета исследуемых образцов. Таким образом, применения системы CIELab является эффективным методом для характеристики и воспроизведения окраски вин.

Исследованные образцы розовых вин были проанализированы с помощью кластерного анализа с учётом координат цвета $\mathrm{a}^{*}$ и b*. Результаты кластеризации представлены ниже на дендрограмме (рис.). Анализ полученного в результате кластеризации иерархического дендрита позволяет выделить в выборке исследованных вин две основные группы (кластера).

В кластер 1 отнесены образцы вин № 1 и № 4 из винограда сортов Саперави и Санджовезе соответственно. Кластер 2 включает варианты № 2 и № 6, а также близкий по хроматическим характеристикам образец № 5 . Наибольшее Эвклидово расстояние характерно для образца вина № 3 из сорта винограда Саперави. 


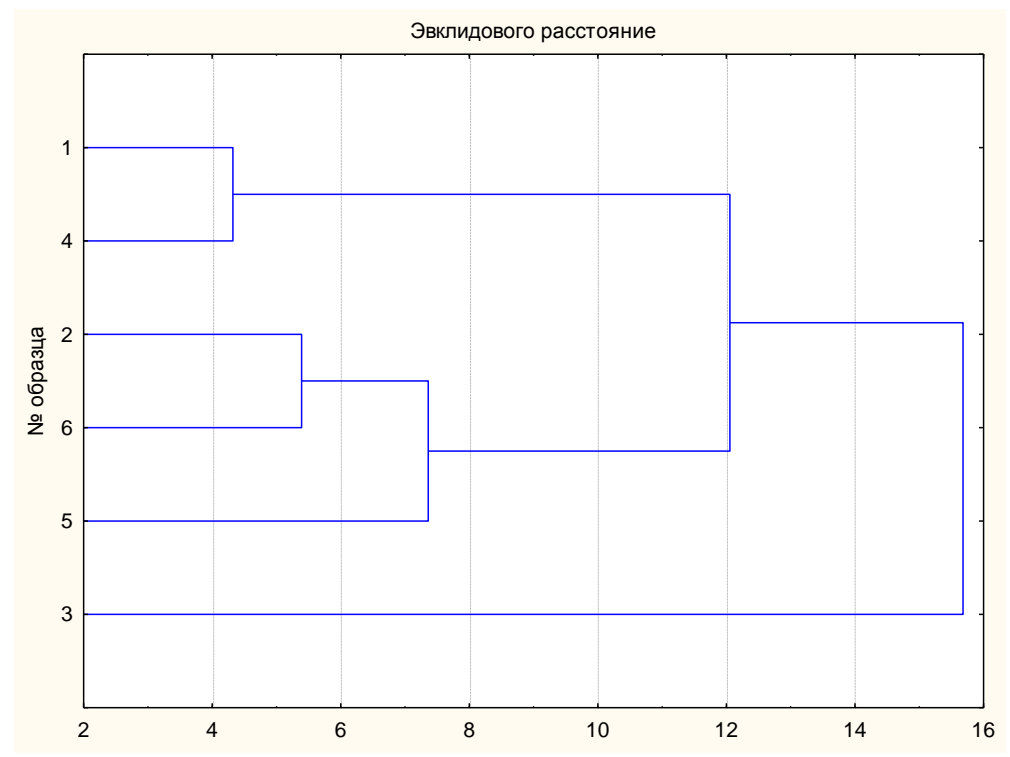

Рис. Дерево зависимости розовых вин по координатам цвета $\mathrm{a}^{*}$ и $\mathrm{b}^{*}$

Полученные данные свидетельствуют о том, что на цветовые характеристики розовых вин влияют не только сортовые особенности, но также существенное влияние может оказывать фенольная зрелость винограда [22], что подтверждается значительным различием цвета образцов из сорта Саперави, а также содержанием мономерных антоцианов и фенольных веществ.

Заключение. Трихроматическая система CIELab позволяет придать математическое выражение цвету вин. Данный способ инструментальной оценки цвета является перспективным способом математического выражения цветовых характеристик для регулирования и управления качеством готовой продукции.

\section{Литература}

1. Білько М.В. Інноваційні технології вітчизняних рожевих столових та ігристих вин: автореф. дис. ... д-ра техн. наук: 05.18.05 / Білько Марина Володимирівна. Київ, 2019. $44 \mathrm{c}$.

2. Dumont A., Heras J. M., Silvano A., Harrop S., Palacios A. Biological management for the preservation of the varietal and fruity characters in rose wine for the international market // Proceedings of the XXIIes Entretiens Scientifiques Lallemand. 2011. P. 37-48.

3. Цветовые характеристики виноматериалов для розовых и красных игристых вин / А.С. Макаров и др. // "Магарач". Виноградарство и виноделие. 2017. № 3. С. 44-47.

4. OIV Focus 2015. The rosé wine market. $17 \mathrm{p}$.

5. ГОСТ 32051-2013. Продукция винодельческая. Методы органолептического анализа. Дата введения 01.07.2014. М.: Стандартинформ, 2013. 16 с. 
6. Musings on the vine - vocabulary and mechanics of wine tasting reference. [Электронный ресурc]: http://www.musing-sonthevine.com/VocabSheet.pdf (дата обращения: 11.07.2018).

7. Билько М.В., Тенетка А.И. Особенности и цветовые характеристики розовых столовых вин // ВиноГрад. 2011. № 11-12 (ноябрь-декабрь). С. 44-46.

8. Analyse de la couleur des vins rosés par Chromamètrie CIE Lab [Электронный pecypc]: $\quad$ https://www.vinseo.com/wp-content/uploads/2016/09/Documentation-CieLab.pdf (дата обращения: 24.07.2019).

9. Masson G. Le nuancier des vins rosés Genèse, mise au point et développement // Coup de Coeur. 2006. 12 p.

10. Аникина Н.С., Червяк С.Н., Гниломедова Н.В. Методы оценки цвета вин. Обзор. Аналитика и контроль. 2019. Т. 23, № 2. С. 158-167. DOI: 10.15826/analitika.2019.23.2.003

11. Jackson R.S. Wine Tasting. A professional handbook, third edition. Academic press, 2017. $430 \mathrm{p}$.

12. Червяк С.Н., Погорелов Д.Ю., Ермихина М.В., Михеева Л.А. Исследование физико-химических показателей подлинных и фальсифицированных красных вин [Электронный ресурс] // Плодоводство и виноградарство Юга России. 2018. № 49(1). C. 152-161. URL: http://journalkubansad.ru/pdf/18/01/13.pdf. (дата обращения: 03.02.2020).

13. Li Si-Yu, Zhu Bao-Qing, Li Li-Jun, Duan Chang-Qing. Extensive and objective wine color classification with chromatic database and mathematical models // International journal of food properties. 2017. V. 20, № 53. PP. 52647-52659.

14. Melendez M.E., Sanchez M.S., Iniguez M., Sarabia L.A., Ortiz M.C. Psychophysical parameters of colour and the chemometric characterisation of wines of the certified denomination of origin 'Rioja' // Analytica chimica Acta. 2001. Vol. 446, № 1-2. PP. 157-167.

15. ГОСТ 33479-2015. Продукты переработки фруктов и овощей. Определение цвета колориметрическим методом. Дата введения 01.07.2016. М.: Стандартинформ, 2015. $17 \mathrm{c}$.

16. Методы технохимического контроля в виноделии // Под ред. В.Г. Гержиковой. Симферополь: Таврида, 2009. 303 с.

17. Аникина Н.С., Погорелов Д.Ю., Михеева Л.А. Определение мономерных антоцианов в виноградных виноматериалах и винах // «Магарач». Виноградарство и виноделие. 2017. № 1. С. 40-43.

18. Method OIV-MA-AS2-11. Determination of chromatic characteristics according to CIELab. Compendium of International Metods of Wine and Must Analysis. 2016. 16 p.

19. Pérez-Caballero V., Ayala F., Echávarri J.F., Negueruela A.I. Proposal for a New Standard OIV Method for Determination of Chromatic Characteristics of Wine // Am. J. Enol. Vitic. 2003. V. 54, № 1. P. 59-62.

20. NIX Color Sensor. Color converter. [Электронный pecypc]: https://nixsensor.com/free-color-converter/ Color converter (дата обращения: 09.07.2019).

21. ГОСТ Р 32030-2013. Вина столовые и виноматериалы столовые. Общие технические условия. Дата введения 01.07.2014. М.: Стандартинформ, 2014. 7 с.

22. Червяк С.Н., Бойко В.А., Левченко С.В. Влияние некорневой подкормки растений на фенольную зрелость винограда и качественные характеристики виноматериалов // Садоводство и виноградарство. 2019. № 4. С. 30-36.

\section{References}

1. Bil'ko M.V. Innovacijni tekhnologiï vitchiznyanih rozhevih stolovih ta igristih vin: avtoref. dis. ... d-ra tekhn. nauk: 05.18.05 / Bil'ko Marina Volodimirivna. Kiïv, 2019. $44 \mathrm{~s}$.

2. Dumont A., Heras J. M., Silvano A., Harrop S., Palacios A. Biological management for the preservation of the varietal and fruity characters in rose wine for the international market // Proceedings of the XXIIes Entretiens Scientifiques Lallemand. 2011. R. 37-48. 
3. Cvetovye harakteristiki vinomaterialov dlya rozovyh i krasnyh igristyh vin / A.S. Makarov i dr. // «Magarach». Vinogradarstvo i vinodelie. 2017. № 3. S. 44-47.

4. OIV Focus 2015. The rosé wine market. $17 \mathrm{r}$.

5. GOST 32051-2013. Produkciya vinodel'cheskaya. Metody organolepticheskogo analiza. Data vvedeniya 01.07.2014. M.: Standartinform, 2013. 16 s.

6. Musings on the vine - vocabulary and mechanics of wine tasting reference. [Elektronnyj resurs]: http://www.musing-sonthevine.com/VocabSheet.pdf (data obrashcheniya: 11.07.2018).

7. Bil'ko M.V., Tenetka A.I. Osobennosti i cvetovye harakteristiki rozovyh stolovyh vin // VinoGrad. 2011. № 11-12 (noyabr'-dekabr'). S. 44-46.

8. Analyse de la couleur des vins rosés par Chromamètrie CIE Lab [Elektronnyj resurs]: https://www.vinseo.com/wp-content/uploads/2016/09/Documentation-CieLab.pdf (data obrashcheniya: 24.07.2019).

9. Masson G. Le nuancier des vins rosés Genèse, mise au point et développement // Coup de Coeur. 2006. 12 r.

10. Anikina N.S., Chervyak S.N., Gnilomedova N.V. Metody ocenki cveta vin. Obzor. Analitika i kontrol'. 2019. T. 23, № 2. S. 158-167. DOI: 10.15826/ analitika.2019.23.2.003

11. Jackson R.S. Wine Tasting. A professional handbook, third edition. Academic press, 2017. $430 \mathrm{p}$.

12. Chervyak S.N., Pogorelov D.YU., Ermihina M.V., Miheeva L.A. Issledovanie fiziko-himicheskih pokazatelej podlinnyh i fal'sificirovannyh krasnyh vin [Elektronnyj resurs] // Plodovodstvo i vi-nogradarstvo YUga Rossii. 2018. № 49(1). S. 152-161. URL: http://journalkubansad.ru/pdf/18/01/13.pdf. (data obrashcheniya: 03.02.2020).

13. Li Si-Yu, Zhu Bao-Qing, Li Li-Jun, Duan Chang-Qing. Extensive and objective wine color classification with chromatic database and mathematical models // International journal of food properties. 2017. V. 20, № 53. RR. 52647-52659.

14. Melendez M.E., Sanchez M.S., Iniguez M., Sarabia L.A., Ortiz M.C. Psychophysical parameters of colour and the chemometric characterisation of wines of the certified denomination of origin 'Rioja' // Analytica chimica Acta. 2001. Vol. 446, № 1-2. PP. 157-167.

15. GOST 33479-2015. Produkty pererabotki fruktov i ovoshchej. Opredelenie cveta kolorimetricheskim metodom. Data vvedeniya 01.07.2016. M.: Standartinform, 2015. 17 s.

16. Metody tekhnohimicheskogo kontrolya v vinodelii // Pod red. V.G. Gerzhikovoj. Simferopol': Tavrida, 2009. 303 s.

17. Anikina N.S., Pogorelov D.YU., Miheeva L.A. Opredelenie monomernyh antocianov v vinogradnyh vinomaterialah i vinah // «Magarach». Vinogradarstvo i vinodelie. 2017. № 1. S. 40-43.

18. Method OIV-MA-AS2-11. Determination of chromatic characteristics according to CIELab. Compendium of International Metods of Wine and Must Analysis. 2016. 16 r.

19. Pérez-Caballero V., Ayala F., Echávarri J.F., Negueruela A.I. Proposal for a New Standard OIV Method for Determination of Chromatic Characteristics of Wine // Am. J. Enol. Vitic. 2003. V. 54, № 1. P. 59-62.

20. NIX Color Sensor. Color converter. [Elektronnyj resurs]: https://nixsensor.com/free-color-converter/ Color converter (data obrashcheniya: 09.07.2019).

21. GOST R 32030-2013. Vina stolovye i vinomaterialy stolovye. Obshchie tekhnicheskie usloviya. Data vvedeniya 01.07.2014. M.: Standartinform, 2014. 7 s.

22. Chervyak S.N., Bojko V.A., Levchenko S.V. Vliyanie nekornevoj podkormki rastenij na fenol'nuyu zrelost' vinograda i kachestvennye harakteristiki vinomaterialov // Sadovodstvo i vinogradarstvo. 2019. № 4. S. 30-36. 